\title{
Impactos dos royalties do petróleo nos indicadores de desenvolvimento dos municípios do Espírito Santo*
}

\section{Impacts of oil royalties in the indicators of development of municipalities in Espírito Santo \\ Impacts des redevances pétrolières dans les indicateurs du développement des villes de Espírito Santo}

\author{
Impactos de regalías petroleras en los indicadores de desarrollo de municipios en \\ Espírito Santo
}

\author{
Sávio Bertochi Caçador ${ }^{* *}$ \\ (sbcacador@hotmail.com) \\ Edson Zambon Monte ${ }^{* * *}$ \\ (edsonzambon@yahoo.com.br)
}

Recebido em 27/04/2012; revisado e aprovado em 23/09/2012; aceito em 10/03/2013

\begin{abstract}
Resumo: Com o revigoramento da indústria petrolífera no Espírito Santo no final dos anos 1990 e início dos anos 2000, torna-se importante estudar os impactos causados pelas participações governamentais nas cidades desse estado. Portanto estimou-se um modelo empírico para avaliar se os royalties afetaram os indicadores municipais de desenvolvimento. Os resultados mostram que os royalties não contribuíram significativamente para a melhoria dos indicadores locais de desenvolvimento.

Palavras-chave: Royalties do petróleo. Desenvolvimento econômico local. Estado do Espírito Santo.

Abstract: With the revival of oil industry in Espírito Santo's territory in late 1990 and early 2000, it becomes important to study the impacts caused by government shares in the State's cities. Therefore, it has been estimated an empirical model to evaluate whether the royalties affected municipal indicators of development. The results show that oil royalties have not contributed significantly to the improvement of local indicators of development. Key words: Oil rents. Local economic development. State of Espírito Santo.

Résumé: Avec l'essor de l'industrie pétrolière dans l'état de Espírito Santo à la fin des années 1990 et début des années 2000, il est important d'étudier les impacts causés par les intérêts du gouvernement dans les villes de cet état. Par conséquent, il a été estimé un modèle empirique pour déterminer si les redevances ont affecté des indicateurs de développement municipal. Les résultats montrent que les redevances n'ont pas considérablement contribué à l'amélioration des indicateurs de développement local.

Mots-clés: Pétrole revenus. Développement économique local. L'état de Espírito Santo.

Resumen: Con el aumento de la actividad petrolera en el Espírit Santo a finales de 1990 y principios de 2000, es importante estudiar los impactos causados por los intereses del Gobierno en las ciudades de ese Estado. Por lo tanto, ha sido estimado un modelo empírico para evaluar si las regalías han afectado a los indicadores de desarrollo municipal. Los resultados muestran que las regalías no han contribuido significativamente a la mejora de los indicadores de desarrollo local.

Palabras clave: Regalías petroleiras. Desarrollo económico local. El estado de Espírito Santo.Introdução
\end{abstract}

\section{Introdução}

O Brasil reformulou o aparato institucional de sua indústria petrolífera em meados dos anos 1990, estabelecendo, dentre outras coisas, novos critérios para as chamadas participações governamentais, isto é, pagamentos a serem realizados pelos concessionários de atividades de exploração e produção de petró- leo e de gás natural. Assim, a lógica inerente a essa legislação é que as regiões direta ou indiretamente afetadas pelas atividades petrolíferas recebam maior parte da compensação financeira repassada pelo governo federal.

Para o Espírito Santo em específico, esse novo marco regulatório da indústria petrolífera trouxe pelo menos dois impactos. No campo estritamente econômico, a produ-

\footnotetext{
* Vale a ressalva de que as opiniões contidas nesse estudo não refletem a opinião do Banco de Desenvolvimento do Espírito Santo (BANDES) ou de algum outro membro dessa instituição.

** Banco de Desenvolvimento do Espírito Santo (BANDES), Vitória, Espírito Santo, Brasil.

*** Universidade Federal do Espírito Santo (UFES), Vitória, Espírito Santo, Brasil.
} 
ção de petróleo e gás natural ressurgiu no estado a partir do final da década de 1990. Com descobertas anunciadas pela Petrobrás e empresas estrangeiras, o estado se tornou a $2^{a}$ maior província petrolífera do país, atrás apenas do Rio de Janeiro. O outro impacto se deu nas finanças públicas dos governos estadual e municipais. A título de exemplo, em Presidente Kennedy, no litoral sul capixaba, a razão entre royalties + participações especiais sobre a receita municipal foi de quase $80 \%$ em 2010 (FREIRE; MAGENTA, 2011), a maior dentre todos os municípios brasileiros.

Dessa forma, torna-se importante estudar os impactos provocados pelas participações governamentais nos municípios espírito-santenses. Assim, estimou-se um modelo empírico para investigar se as rendas petrolíferas distribuídas colaboraram para a melhoria dos indicadores de desenvolvimento dos municípios capixabas no período de 2000 a 2009. Vale dizer que, segundo ANP (2011), desde 2005 todas as cidades do estado recebem royalties, sendo que 15 destas auferem uma quantidade maior desse recurso por serem produtores ou confrontantes com poços de petróleo ${ }^{1}$.

Cabe ressaltar que Postali e Nishijima (2011) já fizeram análises similares às propostas aqui para o conjunto dos municípios brasileiros e serviram de base metodológica para o presente artigo. No entanto, acredita-se que o Espírito Santo precisa de uma investigação específica sobre sua realidade, dado que a distribuição das rendas petrolíferas é heterogênea tanto entre estados como entre cidades, o que é ressaltado pelos autores citados anteriormente.

O restante do artigo se divide em cinco seções. A próxima resume os pontos marcantes do atual marco regulatório das participações governamentais, bem como apresenta os principais estudos sobre os impactos das rendas petrolíferas no Brasil e no Espírito Santo. A terceira seção apresenta os dados mais relevantes sobre a atividade petrolífera e as participações governamentais no estado e seus municípios. A quarta seção explana as bases de dados, as técnicas e os resultados do

\footnotetext{
${ }^{1}$ Esses municípios são: Aracruz, Anchieta, Conceição da Barra, Guarapari, Fundão, Itapemirim, Jaguaré, Linhares, Marataízes, Piúma, Presidente Kennedy, São Mateus, Serra, Vila Velha e Vitória.
}

modelo estimado neste trabalho. Na última seção, por sua vez, tecem-se as considerações finais.

\section{Referencial $^{2}$}

\subsection{Legislação das Participações Governamentais}

Nos anos 1990, o marco regulatório da indústria petrolífera brasileira foi reformulado. O processo teve início com a Emenda Constitucional n. 9/95, que quebrou o monopólio estatal na exploração e refino de petróleo. Em 1997, o Congresso Nacional aprovou a Lei n. 9.478/97 - conhecida como "Lei do Petróleo". Esta lei estabeleceu uma nova lógica para as participações governamentais, que foram definidas pelo Decreto n. 2.705, de 3 de agosto de 1998 - conhecido também como Decreto das Participações Governamentais. Tais participações, que devem estar contidas no contrato de concessão e previstas no edital de licitação, são: i) bônus de assinatura; ii) royalties; iii) participação especial; e, iv) pagamento pela ocupação ou retenção de área ${ }^{3}$.

Os royalties constituem compensação financeira devida pelos concessionários à União, a serem pagos mensalmente, a partir do mês em que um determinado campo começar a produzir. O seu valor será determinado multiplicando-se o equivalente a $10 \%$ do volume total da produção mensal de petróleo e gás natural do campo pelos seus respectivos preços de referência. Com relação ao petróleo, adota-se, como preço de referência, a média ponderada dos preços de venda (sem tributos) praticados pela empresa no respectivo mês, ou um preço mínimo estabelecido pela ANP, aplicando-se o que for maior. No caso do gás natural, o preço de referência será igual à média ponderada dos preços de venda (sem tributos) acordados nos contratos de fornecimento entre concessionário e compradores, deduzidas as tarifas relativas ao transporte do gás até os pontos de entrega.

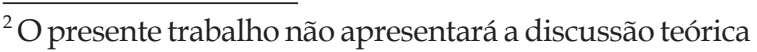
em torno das rendas sobre recursos não renováveis. Para uma revisão dessa literatura, ver Postali e Nishijima (2011).

${ }^{3}$ Por não constarem no objeto de investigação deste artigo, não serão discutidos o bônus de assinatura nem o pagamento pela ocupação ou retenção de área.
} 
No entanto, a alíquota dos royalties pode variar até um mínimo de $5 \%$ sobre o volume de produção do campo. Para fazer isso, a ANP leva em conta riscos geológicos, expectativas de produção e outros fatores como produção em áreas remotas, produção de gás natural não associado ou de petróleo pesado, dificuldades operacionais, inexistência de infraestrutura para escoar a produção, distância até o mercado etc. (BARBOSA, 2001, p. 20). Cabe lembrar que, quando a parcela do valor dos royalties previstos no contrato de concessão equivaler a esse mínimo de $5 \%$, a sua distribuição seguirá o estabelecido na Lei 7.990/89.

A participação especial constitui, por seu turno, compensação financeira extraordinária devida pelos concessionários nos casos de grande volume de produção ou de grande rentabilidade do campo. A sua apuração será feita mediante aplicação de alíquotas progressivas sobre a receita líquida trimestral de cada campo. Tais alíquotas variam em função da localização da lavra, do número de anos de produção e do respectivo volume de produção trimestral fiscalizada. De acordo com Postali (2002, p. 96), o princípio da participação especial é permitir ao governo obter uma parcela maior da renda dos projetos mais lucrativos. As suas alíquotas podem ser de $0 \%, 10 \%, 20 \%, 30 \%, 35 \%$ e $40 \%$.

No que tange à divisão dos recursos dos royalties, a parcela de $5 \%$ é distribuída aos beneficiários de acordo com os critérios constantes da Lei n. 7.990/89 e do Decreto n. 01/91, que a regulamentou, ao passo que a parcela acima de $5 \%$ é distribuída de acordo com os critérios constantes da Lei n. 9.478/97 e do Decreto n. 2.705/98. O quadro 1 apresenta a forma como os recursos dos royalties são repartidos entre os entes federativos.

\begin{tabular}{|c|c|c|}
\hline \multirow{8}{*}{$\begin{array}{c}\text { Parcela } \\
\text { de } 5 \%\end{array}$} & \multirow{3}{*}{ Lavra em terra } & $70 \%$ para estados produtores \\
\hline & & $20 \%$ para municípios produtores \\
\hline & & $\begin{array}{l}\text { 10\% para municípios com instalação de embarque e desembarque } \\
\text { de petróleo e gás natural }\end{array}$ \\
\hline & \multirow{5}{*}{$\begin{array}{l}\text { Lavra na plataforma } \\
\text { continental }\end{array}$} & $30 \%$ para estados confrontantes com poços \\
\hline & & $30 \%$ para municípios confrontantes com poços \\
\hline & & $20 \%$ para Comando da Marinha \\
\hline & & 10\% para Fundo Especial (estados e municípios) \\
\hline & & $\begin{array}{l}\text { 10\% para municípios com instalação de embarque e desembarque } \\
\text { de petróleo e gás natural }\end{array}$ \\
\hline \multirow{10}{*}{$\begin{array}{c}\text { Parcela } \\
\text { acima de } \\
5 \%\end{array}$} & \multirow{4}{*}{ Lavra em terra } & $52,5 \%$ para estados produtores \\
\hline & & 25\% para Ministério de Ciência e Tecnologia \\
\hline & & $15 \%$ para municípios produtores \\
\hline & & $\begin{array}{l}\text { 10\% para municípios com instalação de embarque e desembarque } \\
\text { de petróleo e gás natural }\end{array}$ \\
\hline & \multirow{6}{*}{$\begin{array}{l}\text { Lavra na plataforma } \\
\text { continental }\end{array}$} & 25\% para Ministério de Ciência e Tecnologia \\
\hline & & $22,5 \%$ para estados confrontantes com poços \\
\hline & & $22,5 \%$ para municípios confrontantes com poços \\
\hline & & 15\% para Comando da Marinha \\
\hline & & 7,5\% para Fundo Especial (estados e municípios) \\
\hline & & $\begin{array}{l}\text { 7,5\% para municípios com instalação de embarque e desembarque } \\
\text { de petróleo e gás natural }\end{array}$ \\
\hline
\end{tabular}

Quadro 1 - Distribuição dos royalties

Fonte: Barbosa (2001). Elaboração própria.

No que diz respeito à distribuição dos recursos das participações especiais, ela é regida pelo art. 50 da Lei n. 9.478/97 da seguinte maneira:

- $40 \%$ para o Ministério de Minas e Energia;

- $10 \%$ para o Ministério do Meio Ambiente;

- $40 \%$ para o estado onde ocorrer a produção em terra, ou confrontante com a plataforma continental onde se realizar a produção; 
- $10 \%$ para o município onde ocorrer a produção em terra, ou confrontante com a plataforma continental onde se realizar a produção.

Por último, cabe tecer algumas considerações sobre a aplicação dos royalties e participações especiais originárias das atividades petrolíferas, pois somente essas duas modalidades de renda petrolífera são distribuídas entre os entes da federação brasileira. Em primeiro lugar, a análise da evolução legal das indenizações ou compensações financeiras petrolíferas demonstra que a questão da aplicação dos recursos recebeu pouca atenção ao longo do tempo. Isso fica evidente quando se constata que, até 1986 , não existia instrumento legal que se referia ao controle e à fiscalização de tais recursos. Foi somente a partir deste ano, em que foi promulgada a Lei $7.525 / 86$, que a fiscalização passou a ser feita pelo Tribunal de Constas da União (TCU). Dessa forma, o gestor público possuía total liberdade para gastar tais receitas extraordinárias, desde que observado o interesse público.

Com a edição da Lei 9.478/97, a situação se agravou, uma vez que a abrangência da aplicação dos recursos foi ampliada, pois não fez nenhuma referência acerca da destinação dos recursos das participações governamentais ${ }^{4}$ (royalties + participações especiais). Entretanto permanecem vigentes as restrições impostas pelo Artigo $8^{\circ}$ da Lei $7.990 / 89$, que veda a aplicação dos recursos em pagamento de dívidas e no quadro permanente de pessoal.

Essa flexibilização na aplicação dos recursos das participações governamentais (royalties + participações especiais) foi dilatada ainda mais em 2001, com a publicação da Medida Provisória n. 2.103. O Artigo 16 desta autoriza à União adquirir dos Estados créditos relativos às participações governamentais. Em troca, a União utilizaria em pagamento Certificados Financeiros do Tesouro, que seriam obrigatoriamente utilizados pelos governos estaduais para o pagamento de dívidas com a União e suas entidades, ou na capitalização dos fundos de previdência, a critério do Ministério da Fazenda.

\footnotetext{
4 Doravante entendido como royalties + participações especiais, sendo chamado simplesmente de royalties.
}

Vale destacar também que a descoberta de hidrocarbonetos na camada pré-sal tem suscitado a discussão sobre alterações nos critérios de distribuição das participações governamentais. Mais precisamente, a discussão teve início com a emenda 387/ 2009 ao projeto de lei brasileira n. 5.938 de 2009, que propõe modificações no marco regulatório para a exploração de petróleo na camada présal. Conhecida como emenda Ibsen Pinheiro, basicamente ela propõe que a União fique com $40 \%$ dos royalties e $50 \%$ da participação especial da produção de petróleo em mar, ao passo que o restante dos recursos seria dividido entre estados e municípios, seguindo as regras do Fundo de Participação dos municípios e dos estados.

Depois de vetada a emenda Ibsen Pinheiro, a discussão evoluiu para o projeto de lei $2.565 / 2011$. Tal projeto determina a redução de $50 \%$ para $42 \%$ da parcela da União na participação especial. Em relação aos royalties, o projeto propõe uma redução de $30 \%$ para $20 \%$ na fatia destinada ao governo federal. Para compensar o governo estadual, foi proposto que, a partir de 2013, a União receba uma compensação na participação especial de $1 \%$ por ano, até chegar a $46 \%$ em 2016. Já para os estados produtores, a sua parcela de royalties seria reduzida de $26,25 \%$ para $20 \%$ e a participação especial cairia de $40 \%$ para $20 \%$. Contudo o Deputado Carlos Zarattini apresentou um substitutivo à emenda 2.565/11, permitindo a manutenção, até 2020, da receita auferida por estados e municípios produtores em $2011^{5}$.

\subsection{Revisão da literatura}

Em função do montante crescente de recursos e da importância cada vez maior que estes representam para muitas regiões do país, alguns trabalhos têm estudado a relação entre os royalties recebidos por uma localidade e seu grau de desenvolvimento social. Leal e Serra (2002), por exemplo, analisam a aplicação das receitas de royalties em municípios do norte fluminense. Os autores concluem que os

\footnotetext{
5 Essas propostas ainda estão em discussão no Congresso Nacional. De qualquer forma, ressalta-se que não é o propósito deste trabalho discutir os impactos das alterações de critérios das participações governamentais sobre o Espírito Santo e seus municípios.
} 
municípios contemplados com essas receitas, na forma da nova lei, destinaram recursos para investimentos em volume superior à média do estado, mas o valor desse investimento tem se mostrado sistematicamente menor que o montante de royalties recebido.

Sobre o caso específico do município de Campos dos Goytacazes - o maior beneficiário de rendas do petróleo, em termos brutos -, Navarro (2003) avaliou que seu Índice de Desenvolvimento Humano (IDH) evoluiu ligeiramente acima de cidades similares ao longo da década de 1990. Esse município também aumentou seus investimentos em saneamento e em infraestrutura, mas numa proporção menor do que as rendas recebidas de petróleo.

Já Costa Nova (2005) examinou diversos indicadores sociais de alguns municípios baianos que receberam valores expressivos de royalties. A principal conclusão é que, apesar da situação orçamentária favorável, essas cidades não expandiram significativamente seus indicadores sociais quando comparados com municípios que não têm direito a esses recursos.

Bregman (2007) investigou a relação entre as receitas de royalties e as despesas de capital em municípios dependentes de recursos do petróleo para o período de 1999 a 2005 em todo o país. As conclusões apontaram que os municípios cujos orçamentos mais dependem de rendas do petróleo investiram em igual proporção ao ingresso de tais receitas.

Diferentemente dos trabalhos anteriores, Postali (2007) avaliou o impacto das rendas petrolíferas sobre o crescimento econômico dos municípios beneficiados pela nova legislação. As conclusões indicam uma relação inversa entre receitas de royalties e crescimento do PIB municipal per capita após o ano 2000, momento a partir do qual os recursos do petróleo cresceram substancialmente em função do choque cambial e do aumento do preço do barril.

Caselli e Michaels (2009) elaboraram um estudo acerca dos efeitos dos royalties sobre indicadores sociais de localidades brasileiras, assim como sobre suas despesas. As principais conclusões foram: 1) as receitas extraordinárias do petróleo de fato geram algum aumento em despesas ligadas à qualidade social, como infraestrutura urbana, saúde e educação; e 2) os indicadores sociais não responderam satisfatoriamente ao aumento desses recursos.

Queiroz e Postali (2010) investigaram se o advento das receitas de royalties reduziu o esforço fiscal das localidades atualmente contempladas. Para isso, eles utilizaram o método de fronteiras estocásticas de produção com efeitos de ineficiência. Nesse modelo, as arrecadações tributárias foram consideradas variáveis de produção dependentes e as ineficiências na arrecadação tributária foram modeladas como função das rendas do petróleo. Os resultados mostram a existência de uma relação positiva entre o grau de dependência de royalties e participações especiais - medido pela participação desses recursos nas receitas correntes dos municípios - e as ineficiências técnicas na coleta dos impostos municipais. Trata-se de um indício de que o usufruto de rendas do petróleo reduz o esforço fiscal dos municípios beneficiados.

Monteiro e Ferraz (2010) examinam os mecanismos de política econômica que conectam abundância de recursos e desenvolvimento econômico, analisando o recente aumento na produção de petróleo do Brasil e os pagamentos de royalties do petróleo feitos aos municípios. Eles mostram que os pagamentos de royalties criam uma grande vantagem nas duas eleições que seguem o boom inesperado do petróleo, mas esse efeito desaparece no médio prazo.

Postali e Nishijima (2011) investigaram se os royalties distribuídos sob a lei 9.478/97 contribuíram para a melhoria dos indicadores sociais dos municípios contemplados, em relação à média nacional, no período de 2000 a 2007. Os resultados mostram que as rendas do petróleo não produziram impactos significativos nos indicadores sociais de saúde e de educação dos municípios beneficiados, mas geraram efeitos negativos sobre seus setores formais de trabalho.

Carnicelli e Postali (2012a) investigaram se as transferências de rendas petrolíferas levam as prefeituras beneficiadas a aumentarem a contratação de funcionários públicos, em desacordo com as recomendações legais. Para isso, aplicou-se o método Duplamente Robusto a um painel de municípios observados entre 2000 e 2009. Os resultados mostram que as prefeituras elevam o seu quadro de 
funcionários diante do usufruto de rendas do petróleo, mas a despesa média com pessoal não aumenta nas cidades pertencentes ao grupo de tratamento. No Rio de Janeiro, sujeito a determinações mais específicas de seu Tribunal de Contas, o efeito não é significativo, indicando a aderência das prefeituras às regras.

Por fim, Carnicelli e Postali (2012b) investigaram se os repasses de royalties reduzem o esforço próprio de arrecadação tributária das cidades contempladas. Para isso, aplicouse o método Duplamente Robusto a um painel de municípios observados entre 2000 e 2009. Os resultados mostram que existe um efeito negativo dessas transferências sobre o esforço fiscal das cidades beneficiadas. No entanto semelhante resultado não se verifica quando computado o efeito médio sobre todas as cidades brasileiras.

No caso do Espírito Santo, são poucos os estudos sobre os impactos dos royalties no bem-estar ou no crescimento econômico de seus municípios. Grassi e Caçador (2007), por exemplo, analisam o impacto das rendas petrolíferas sobre as receitas e despesas do governo estadual e das seis localidades capixabas que mais receberam esses recursos entre 2000 e 2005. Quanto ao governo estadual, notou-se que os royalties ainda não representavam parcela significativa do seu orçamento. Mesmo assim, isso não impediu que fosse feito um acordo para pagamento de dívidas com o governo federal com base em receitas futuras desses recursos. No que tange aos municípios, comprovou-se que, em alguns deles, já existia uma dependência razoável, embora as despesas de capital não tenham crescido na mesma proporção.

Por outro lado, Ribeiro et al. (2010) estudaram os efeitos dos royalties no PIB dos 78 municípios capixabas entre 1999 e 2004. Usando a metodologia de dados em painel equilibrado, mostraram que as rendas petrolíferas não impactaram os PIBs municipais.

\section{Atividade petrolífera e royalties no Espírito Santo: dados relevantes}

A presente seção apresenta, de forma sucinta, os principais dados sobre a produção de gás natural e petróleo, bem como a distribuição de royalties aos municípios capixabas.
O objetivo é comparar a evolução, entre 2000 e 2009 - período tomado como base para o presente estudo -, do Espírito Santo relativamente ao Rio de Janeiro, a maior província petrolífera do país, e ao Brasil.

Nessa linha, dados da ANP (2011) mostram que a produção de gás natural em território capixaba era de 317 milhões de $\mathrm{m}^{3} \mathrm{em} 2000$, cerca de $5,5 \%$ da carioca e $2,4 \%$ da nacional. Já em 2009, o estado alcançou a marca de 1,1 bilhão de $\mathrm{m}^{3}$ produzidos, representando $10,3 \%$ da produção do Rio de Janeiro e 5,1\% da brasileira. Tal produção cresceu vertiginosamente no período 2000-2009, a uma média anual de $23,9 \%$. Esse percentual supera, em muito, a expansão de 8,3\% do Rio de Janeiro e 5,9\% da brasileira. Vale destacar que, a partir de 2006, o aumento da produção capixaba se desloca da nacional e da carioca, basicamente por conta da inauguração da Plataforma de Peroá e da Unidade de Tratamento de Gás de Cacimbas.

Dando continuidade, estatísticas da ANP (2011) mostram que a produção de petróleo no Espírito Santo era de 4,7 milhões de barris em 2000, representando cerca de $1,3 \%$ da carioca e $1 \%$ da nacional. Já em 2009, o estado atingiu o valor de 35,9 milhões de barris produzidos, $5,9 \%$ da produção do Rio de Janeiro e 5,1\% da brasileira. A produção local de petróleo cresceu exponencialmente entre 2000 e 2009, a uma média anual de $67 \%$. Esse percentual é bem superior à expansão de $6,9 \%$ do Rio de Janeiro e 5,8\% da brasileira. Salienta-se que, a partir de 2002, o aumento da produção capixaba se desloca da nacional e da carioca, sobretudo em razão do início da produção em águas profundas no campo de Jubarte, ainda em 2002, e do começo da produção do campo de Golfinho, em 2006.

Em função da crescente produção de gás e óleo no Espírito Santo, a distribuição de royalties para os seus municípios também aumentou significativamente. Dados da ANP (2011) mostram que as rendas petrolíferas transferidas às localidades capixabas cresceram substancialmente entre 2000 e 2009, a uma média anual de $134 \%$, muito superior ao aumento da produção de gás e óleo. Esse percentual é superior à expansão de $46,5 \%$ e $57,6 \%$ para as cidades do Rio de Janeiro e do Brasil, respectivamente.

Finalmente, a tabela 1 apresenta os valores de royalties recebidos pelos municípios 
capixabas entre os anos de 2000 e de 2009. Tal tabela explicita a heterogeneidade da distribuição desses recursos: I) as cidades produtoras de petróleo e gás ou confrontantes com poços concentraram $88,4 \%$ do montante auferido em 2009; e II) somente três localidades (Presidente Kennedy, Linhares e São Mateus) responderam por $62,2 \%$ do total recebido pelas cidades espírito-santenses.

Tabela 1 - Royalties + Participações Especiais recebidos pelos municípios do ES (2000/2009), a preços constantes (IPCA $2000=100$ )

\begin{tabular}{l|c|c|c|c}
\hline Beneficiários & $\mathbf{2 0 0 0}$ (R\$ mil) & $\begin{array}{c}\text { Part. Relativa } \\
\text { em 2000 (\%) }\end{array}$ & $\mathbf{2 0 0 9}$ (R\$ mil) & $\begin{array}{c}\text { Part. Relativa } \\
\text { em 2009 (\%) }\end{array}$ \\
\hline Anchieta & 2 & 0,02 & 2.063 & 1,06 \\
Aracruz & 0 & 0,00 & 11.467 & 5,89 \\
Conceição da Barra & 337 & 3,25 & 1.239 & 0,64 \\
Fundão & 0 & 0,00 & 3.108 & 1,60 \\
Guarapari & 1 & 0,01 & 487 & 0,25 \\
Itapemirim & 0 & 0,00 & 11.923 & 6,13 \\
Jaguaré & 402 & 3,87 & 4.975 & 2,56 \\
Linhares & 4.684 & 45,16 & 28.529 & 14,66 \\
Marataízes & 0 & 0,00 & 4.255 & 2,19 \\
Piúma & 0 & 0,00 & 616 & 0,32 \\
Presidente Kennedy & 458 & 4,42 & 79.189 & 40,70 \\
São Mateus & 2.651 & 25,56 & 13.256 & 6,81 \\
Serra & 0 & 0,00 & 6.504 & 3,34 \\
Vila Velha & 1 & 0,01 & 3.034 & 1,56 \\
Vitória & 1.808 & 17,43 & 3.334 & 1,71 \\
Total Municípios Produtores & 10.345 & 99,73 & 173.979 & 89,41 \\
Demais municípios & 28 & 0,27 & 20.608 & 10,59 \\
Total Municípios do ES & 10.373 & 100,00 & 194.587 & 100,00 \\
\hline
\end{tabular}

Fonte: ANP (2011).

\section{Procedimentos empíricos}

\subsection{Metodologia e base de dados}

Tal como feito por Postali e Nishijima (2011) para o Brasil, para investigar se as rendas do petróleo impactaram positivamente os indicadores de desenvolvimento dos municípios capixabas ao longo da última década, utilizou-se o Índice Firjan de Desenvolvimento Municipal (IFDM), elaborado pela Federação das Indústrias do Estado do Rio de Janeiro (Firjan). Trata-se de uma medida alternativa ao Índice de Desenvolvimento Humano (IDH), e agrega diversos indicadores sociais, com o mesmo objetivo de definir o grau de desenvolvimento municipal.

Conforme explicitado em Firjan (2011), o IFDM é calculado a partir da média aritmética simples de três componentes relativos a indicadores de Educação, Saúde e Emprego e Renda. Da mesma forma que o IDH, o IFDM varia entre 0 e 1 .

Como o objetivo deste trabalho foi avaliar se as participações governamentais afetaram a variação dos indicadores de desenvolvimento das cidades capixabas, estimou-se o seguinte modelo de efeitos fixos:

$I F D M_{i t}=\alpha+\mathrm{f}_{\mathrm{i}}+\beta_{1} \mathrm{ROY}_{\mathrm{it}}+\beta_{2} \mathrm{PIBPC}_{\mathrm{it}}+\beta_{3} \mathrm{POP}_{\mathrm{it}}+\varepsilon_{\mathrm{it}}$,

onde:

- $I_{F D M_{i t}}=$ logaritmo natural do IFDM para o município $i$ no ano $t$;

- $R O Y_{i t}=$ logaritmo natural do total de royalties e participações especiais per capita recebidos pelo município $i$ no ano $t$;

- $P I B P C_{i t}=$ logaritmo natural do PIB per capita do município $i$ no ano $t^{6}$;

- $P O P_{i t}=$ logaritmo natural da população municipal;

\footnotetext{
${ }^{6}$ Diferentemente de Postali e Nishijima (2011), este trabalho apenas transformou a variável IFDM em logaritmo.
} 
Na Equação (1), $f_{i}$ é o efeito fixo do município $i$, $\alpha$ é a constante de estimação e $\varepsilon_{\text {it }}$ um ruído branco. $\mathrm{O}$ modelo de efeitos fixos permite controlar as características não observáveis das localidades, mas que permanecem constantes ao longo do tempo. Dummies de ano foram inseridas nas estimações, visando controlar choques macroeconômicos globais. A hipótese de identificação é de que $\mathrm{E}\left[\varepsilon_{\mathrm{it}} \mid \mathrm{ROY} \mathrm{Y}_{\mathrm{it}}\right]=0$, ou seja, não deve existir correlação entre os royalties e as demais variáveis não controladas no modelo, a fim de que o coeficiente estimado seja apropriadamente identificado (WOOLDRIDGE, 2002). Essa é uma hipótese aceitável, pois as distorções na distribuição dos royalties são controladas por efeitos fixos.

No que tange à variável de interesse, utilizou-se a razão royalties+participações especiais em relação à população. Ela tem como propósito investigar a relação entre abundância destes recursos e os indicadores de desenvolvimento em foco. Vale dizer que o IFDM está calculado para os anos de 2000, 2005, 2006, 2007, 2008 e 2009, que constituem o período estudado neste trabalho.

As duas variáveis monetárias, royalty per capita e PIB per capita, estão a preços constantes de 2000, deflacionadas pelo Índice de Preços ao Consumidor Amplo (IPCA). As fontes dos dados foram: Firjan (2011) para IFDM, IFDM Educação, IFDM Saúde e IFDM Emprego e Renda; IBGE (2011) para PIB e população; ANP (2011): royalties. A Tabela 2 resume as estatísticas descritivas das variáveis utilizadas no estudo ${ }^{7}$.

Tabela 2 - Estatísticas Descritivas

\begin{tabular}{|c|c|c|c|c|c|c|c|c|}
\hline \multirow{3}{*}{ Variáveis } & \multicolumn{4}{|c|}{2000} & \multicolumn{4}{|c|}{2005} \\
\hline & \multicolumn{2}{|c|}{ Produtores } & \multicolumn{2}{|c|}{ Não-produtores } & \multicolumn{2}{|c|}{ Produtores } & \multicolumn{2}{|c|}{ Não-produtores } \\
\hline & Média & D.P. & Média & D.P. & Média & D.P. & Média & D.P. \\
\hline IFDM & 0,625 & 0,076 & 0,567 & 0,062 & 0,718 & 0,088 & 0,659 & 0,059 \\
\hline IFDM Educação & 0,662 & 0,057 & 0,639 & 0,077 & 0,726 & 0,056 & 0,707 & 0,073 \\
\hline IFDM Saúde & 0,736 & 0,087 & 0,679 & 0,072 & 0,808 & 0,075 & 0,784 & 0,062 \\
\hline IFDM Renda e Emprego & 0,477 & 0,149 & 0,383 & 0,102 & 0,619 & 0,192 & 0,487 & 0,119 \\
\hline Royalty per capita & 10,56 & 16,55 & 0,03 & 0,01 & 153,25 & 334,48 & 2,92 & 1,38 \\
\hline PIB per capita & 9.083 & 6.856 & 4.410 & 1.071 & 19.937 & 18.110 & 7.128 & 2.513 \\
\hline População & 98.470 & 119.334 & 26.132 & 46.002 & 111.686 & 136.521 & 27.792 & 50.297 \\
\hline \multirow{3}{*}{ Variáveis } & \multicolumn{4}{|c|}{2006} & \multicolumn{4}{|c|}{2007} \\
\hline & \multicolumn{2}{|c|}{ Produtores } & \multicolumn{2}{|c|}{ Não-produtores } & \multicolumn{2}{|c|}{ Produtores } & \multicolumn{2}{|c|}{ Não-produtores } \\
\hline & Média & D.P. & Média & D.P. & Média & D.P. & Média & D.P. \\
\hline IFDM & 0,727 & 0,095 & 0,657 & 0,057 & 0,732 & 0,088 & 0,664 & 0,057 \\
\hline IFDM Educação & 0,723 & 0,047 & 0,712 & 0,064 & 0,766 & 0,039 & 0,760 & 0,055 \\
\hline IFDM Saúde & 0,813 & 0,068 & 0,792 & 0,059 & 0,821 & 0,071 & 0,799 & 0,064 \\
\hline IFDM Renda e Emprego & 0,723 & 0,047 & 0,712 & 0,064 & 0,609 & 0,196 & 0,433 & 0,113 \\
\hline Royalty per capita & 336,26 & 615,63 & 21,43 & 10,04 & 357,76 & 652,42 & 32,47 & 15,38 \\
\hline PIB per capita & 37.673 & 29.946 & 14.487 & 4.572 & 33.594 & 26.467 & 12.335 & 3.874 \\
\hline População & 114.061 & 139.646 & 28.118 & 51.120 & 112.053 & 139.700 & 27.204 & 50.890 \\
\hline \multirow{3}{*}{ Variáveis } & \multicolumn{4}{|c|}{2008} & \multicolumn{4}{|c|}{2009} \\
\hline & \multicolumn{2}{|c|}{ Produtores } & \multicolumn{2}{|c|}{ Não-produtores } & \multicolumn{2}{|c|}{ Produtores } & \multicolumn{2}{|c|}{ Não-produtores } \\
\hline & Média & D.P. & Média & D.P. & Média & D.P. & Média & D.P. \\
\hline IFDM & 0,735 & 0,091 & 0,670 & 0,052 & 0,740 & 0,085 & 0,684 & 0,048 \\
\hline IFDM Educação & 0,789 & 0,041 & 0,783 & 0,050 & 0,810 & 0,053 & 0,806 & 0,044 \\
\hline IFDM Saúde & 0,836 & 0,065 & 0,817 & 0,064 & 0,845 & 0,064 & 0,833 & 0,060 \\
\hline IFDM Renda e Emprego & 0,580 & 0,224 & 0,413 & 0,110 & 0,565 & 0,188 & 0,414 & 0,109 \\
\hline Royalty per capita & 711,55 & $1.921,72$ & 43,82 & 20,69 & 858,96 & $2.682,46$ & 30,56 & 14,40 \\
\hline PIB per capita & 32.842 & 35.200 & 9.508 & 2.818 & 38.559 & 40.833 & 13.189 & 3.636 \\
\hline População & 114.243 & 140.781 & 27.898 & 51.323 & 116.082 & 145.891 & 27.524 & 52.327 \\
\hline
\end{tabular}

Fonte: elaboração própria, com base nos dados da Firjan (2011), IBGE (2011) e ANP (2011).

Nota: D.P. significa desvio-padrão.

\footnotetext{
7 O Espírito Santo possui 78 municípios, porém, o presente estudo trabalhou com uma amostra de 77 localidades. A justificativa é que Governador Lindenberg foi instalado em 2001 e não possui qualquer estatística anterior a esta data.
} 


\subsection{Resultados}

Em todos dos casos, o teste de JarqueBera (JB) demonstrou, nas estimativas por Mínimos Quadrados Ordinários (MQO), que os erros não possuem distribuição normal. Wooldridge (2002) salienta que o método de Mínimos Quadrados Generalizados (MQG) diminui os impactos da não normalidade dos resíduos sobre o modelo estimado e, neste caso, é possível aceitá-la, mesmo ela persistindo após a estimação da regressão desejada. Assim, para as estimativas, adotou-se o método de $\mathrm{MQG}^{8}$, com efeitos fixos ${ }^{9}$. Também, para todos os modelos, com o intuito de obter erros padrões robustos, foi utilizado o método de covariância do coeficiente (coeficient covariance method) Cross-Section SUR (PCSE).

Na tabela 3 são apresentados os resultados referentes ao IFDM Total. Observa-se que a principal variável testada, royalties per capita, não é estatisticamente significante, ou seja, esses recursos não influenciaram as cidades capixabas em uma evolução diferenciada nos seus indicadores de desenvolvimento. Já as dummies para os anos e a variável população não obtiveram os sinais esperados, mas se mostraram significativas em todos os casos.

Tabela 3 - Resultado do modelo com variável dependente IFDM Total

\begin{tabular}{lccrc}
\hline \multicolumn{1}{c}{ Variáveis } & Coeficientes & Erro-padrão & Valor t & P-valor \\
\hline Royalty per capita & $-0,000504^{\text {ns }}$ & 0,002268 & $-0,222349$ & 0,824200 \\
População & $-0,186371^{* * *}$ & 0,020917 & $-8,909911$ & 0,000000 \\
PIB per capita & $0,018601^{* * *}$ & 0,006635 & 2,803267 & 0,005300 \\
Dummy 2005 & $0,141195^{* * *}$ & 0,009601 & 14,706150 & 0,000000 \\
Dummy 2006 & $0,129620^{* * *}$ & 0,015622 & 8,297431 & 0,000000 \\
Dummmy 2007 & $0,141373^{* * *}$ & 0,015882 & 8,901556 & 0,000000 \\
Dummy 2008 & $0,155078^{* * *}$ & 0,015895 & 9,756595 & 0,000000 \\
Dummy 2009 & $0,167277^{* * *}$ & 0,016082 & 10,401720 & 0,000000 \\
Constante & $1,143927^{* * *}$ & 0,205573 & 5,564579 & 0,000000 \\
R $^{2}$ ajustado & \multicolumn{3}{c}{0,975073} \\
Estatística F $(77,452)$ & \multicolumn{3}{c}{$462,6818[0,0000]$} \\
N. de observações & \multicolumn{3}{c}{77} \\
N. de municípios & \multicolumn{5}{c}{} \\
\hline
\end{tabular}

Fonte: elaborado pelos autores com base nos dados da pesquisa.

Notas: 1) *** Significativo a 1\%; ns Para não significativo; 2) Utilizou-se o método de Mínimos Quadrados Generalizados (Cross-Section SUR - PCSE), com efeitos fixos.

No que tange ao IFDM Educação (tabela 4), o efeito dos royalties sobre a evolução deste indicador nas cidades espírito-santenses foi muito pequeno e negativo (-0,0023\%). Quanto à dummies para ano e a variável população, elas não obtiveram os sinais esperados, embora tenham se mostrado significativas em todas as situações. Por fim, o modelo se mostrou bem ajustado ( $\mathrm{R}^{2}$ ajustado igual a $98,3 \%$ ) e globalmente significativo (Teste F significativo a $1 \%)$.

\footnotetext{
8 Para detalhes do método de MQG, consultar Wooldridge (2002, cap. 10).

9 Em todas as estimativas, o teste de Hausman demonstrou que se deve rejeitar a hipótese nula de que o modelo de efeitos aleatórios apresenta estimadores mais consistentes e eficientes do que o modelo de efeitos fixos.
} 
Tabela 4 - Resultado do modelo com variável dependente IFDM Educação

\begin{tabular}{|c|c|c|c|c|}
\hline Variáveis & Coeficientes & Erro-padrão & Valor $\mathbf{t}$ & P-valor \\
\hline Royalty per capita & $-0,002369 *$ & 0,001401 & $-1,691437$ & 0,091600 \\
\hline População & $-0,268342^{* * *}$ & 0,060660 & $-4,423683$ & 0,000000 \\
\hline PIB per capita & $0,018335^{* *}$ & 0,007742 & 2,368298 & 0,018400 \\
\hline Dummy 2005 & $0,107991^{* * *}$ & 0,007799 & 13,847040 & 0,000000 \\
\hline Dummy 2006 & $0,105869 * * *$ & 0,013689 & 7,733647 & 0,000000 \\
\hline Dummy 2007 & $0,172638^{* * *}$ & 0,013183 & 13,095920 & 0,000000 \\
\hline Dummy 2008 & $0,209271^{* * *}$ & 0,012601 & 16,607700 & 0,000000 \\
\hline Dummy 2009 & $0,234625^{\star * *}$ & 0,013734 & 17,084070 & 0,000000 \\
\hline Constante & $2,057583^{* * *}$ & 0,593229 & 3,468445 & 0,000600 \\
\hline $\mathrm{R}^{2}$ ajustado & \multicolumn{4}{|c|}{0,982845} \\
\hline Estatística F $(77,452)$ & \multicolumn{4}{|c|}{$315,4328[0,0000]$} \\
\hline N. de observações & \multicolumn{4}{|c|}{462} \\
\hline N. de municípios & \multicolumn{4}{|c|}{77} \\
\hline
\end{tabular}

Fonte: elaborado pelos autores com base nos dados da pesquisa.

Notas: 1) *** Significativo a 1\%; ** Significativo a 5\%; * Significativo a 10\%; 2) Utilizou-se o método de Mínimos Quadrados Generalizados (Cross-Section SUR - PCSE), com efeitos fixos.

Sobre o IFDM Saúde (tabela 5), a variável "royalty per capita" se mostrou positiva e significante, embora o efeito marginal seja muito pequeno $(0,0064 \%)$. Como se pode observar, as variáveis de controle não obtiveram os sinais esperados e são significantes, com exceção do "PIB per capita" neste último caso.

Tabela 5 - Resultado do modelo com variável dependente IFDM Saúde

\begin{tabular}{lccrc}
\hline \multicolumn{1}{c}{ Variáveis } & Coeficientes & Erro-padrão & Valor t & P-valor \\
\hline Royalty per capita & $0,006496^{* * *}$ & 0,000762 & 8,529083 & 0,000000 \\
População & $-0,398767^{* * *}$ & 0,040050 & $-9,956673$ & 0,000000 \\
PIB per capita & $0,001481^{\text {ns }}$ & 0,007468 & 0,198356 & 0,842900 \\
Dummy 2005 & $0,108112^{* * *}$ & 0,006267 & 17,251080 & 0,000000 \\
Dummy 2006 & $0,110005^{* * *}$ & 0,012574 & 8,748371 & 0,000000 \\
Dummy 2007 & $0,121910^{* * *}$ & 0,011622 & 10,489140 & 0,000000 \\
Dummy 2008 & $0,142583^{* * *}$ & 0,010880 & 13,105240 & 0,000000 \\
Dummy 2009 & $0,162778^{* * *}$ & 0,013033 & 12,489620 & 0,000000 \\
Constante & $3,593651^{* * *}$ & 0,425471 & 8,446280 & 0,000000 \\
$R^{2}$ ajustado & \multicolumn{3}{c}{0,994132} \\
Estatística F $(77,452)$ & \multicolumn{5}{c}{$4630,7051[0,0000]$} \\
N. de observações & \multicolumn{3}{c}{77} \\
N. de municípios & \multicolumn{5}{c}{} \\
\hline
\end{tabular}

Fonte: elaborado pelos autores com base nos dados da pesquisa.

Notas: 1) ** Significativo a 1\%; ns Para não significativo; 2) Utilizou-se o método de Mínimos Quadrados Generalizados (Cross-Section SUR - PCSE), com efeitos fixos.

No que diz respeito ao IFDM Emprego e Renda (tabela 6), a variável "royalty per capita" não se mostrou significativa. Além disso, "PIB per capita" e algumas variáveis de controle não se mostraram significativas. Por fim, o modelo se mostrou bem ajustado ( $\mathrm{R}^{2}$ ajustado igual a 90,9\%) e globalmente significativo (Estatística F significativa a $1 \%)$. 
Tabela 6 - Resultado do modelo com variável dependente IFDM Emprego e Renda

\begin{tabular}{l|ccrc}
\hline \multicolumn{1}{c}{ Variáveis } & Coeficientes & Erro-padrão & Valor t & P-valor \\
\hline Royalty per capita & $-0,004785^{\text {ns }}$ & 0,023886 & $-0,200329$ & 0,841300 \\
População & $0,746063^{* * *}$ & 0,278864 & 2,675363 & 0,007800 \\
PIB per capita & $-0,006858^{\text {ns }}$ & 0,044150 & $-0,155330$ & 0,876600 \\
Dummy 2005 & $0,250019^{* *}$ & 0,106314 & 2,351708 & 0,019200 \\
Dummy 2006 & $0,632878^{* * *}$ & 0,159041 & 3,979335 & 0,000100 \\
Dummy 2007 & $0,150421^{\text {ns }}$ & 0,164686 & 0,913379 & 0,361600 \\
Dummy 2008 & $0,100581^{\text {ns }}$ & 0,169036 & 0,595028 & 0,552200 \\
Dummy 2009 & $0,119149^{\text {ns }}$ & 0,164536 & 0,724148 & 0,469400 \\
Constante & $-8,318752^{* * *}$ & 2,835467 & $-2,933820$ & 0,003600 \\
R $^{2}$ ajustado & \multicolumn{5}{c}{0,909522} \\
Estatística F $(77,452)$ & \multicolumn{5}{c}{$46,16871[0,0000]$} \\
N. de observações & \multicolumn{3}{c}{762} \\
N. de municípios & \multicolumn{5}{c}{} \\
\hline
\end{tabular}

Fonte: elaborado pelos autores com base nos dados da pesquisa.

Notas: 1) *** Significativo a 1\%; ** Significativo a 5\%; ns Para não significativo; 2) Utilizou-se o método de Mínimos Quadrados Generalizados (Cross-Section SUR - PCSE), com efeitos fixos.

\section{Considerações finais}

O volume de royalties recebidos pelas prefeituras capixabas passou de $\mathrm{R} \$ 10,3$ milhões, em 2000, para R\$194,5 milhões - a preços de 2000, corrigidos pelo IPCA -, em 2009. Portanto, no período estudado no presente trabalho, as rendas petrolíferas tiveram uma expansão de 177,6\% ao ano, em média. Em valor per capita, os royalties passaram de $R \$ 3,35$ para $R \$ 56,41$ no mesmo espaço de tempo. Esses números mostram o quão relevante tem se tornado essa questão para os municípios espírito-santenses nos últimos anos, bem como quão importante é avaliar os seus impactos sociais, alvo deste trabalho.

Dessa maneira, estimou-se um modelo empírico objetivando investigar se as rendas petrolíferas contribuíram para a melhoria de indicadores de desenvolvimento dos municípios capixabas beneficiados no período de 2000 a 2009. Os principais resultados foram os seguintes:

i. no que se refere ao IFDM, os royalties não impactaram no avanço desse indicador;

ii. para o IFDM Educação, o efeito dos royalties sobre a evolução desse indicador nas cidades espírito-santenses foi muito pequeno e negativo $(-0,0023 \%)$, embora tenha sido positivo nas localidades produtoras; iii. quanto ao IFDM Saúde, a variável "royalty per capita" se mostrou positiva e significante, embora o efeito marginal seja muito pequeno $(0,0064 \%)$;

iv. por fim, o resultado do IFDM Emprego e Renda mostrou que os royalties não afetaram o desempenho desse indicador.

Resumindo, os resultados econométricos realizados apontaram que os royalties impactaram positivamente o indicador de saúde, e negativamente, o indicador de educação, mas não afetaram o IFDM Total e o de Emprego e Renda. Dessa maneira, pode-se afirmar que os royalties não contribuíram significativamente para a melhoria dos indicadores de desenvolvimento das cidades espírito-santenses.

Vale citar que, localmente, a lei 8.308, de 2006, instituiu o Fundo para a Redução das Desigualdades Regionais, cujo objetivo é transferir aos municípios parcela dos recursos da compensação financeira repassada ao governo estadual pelo resultado da exploração do petróleo e do gás natural. A distribuição é feita levando em consideração a população, o percentual de repasse do Imposto sobre Circulação de Mercadorias e Serviços (ICMS) e a condição de não ser grande recebedor de royalties. Embora o objetivo deste trabalho não seja avaliar os impactos dessa lei, os resultados mostrados evidenciam a necessidade de fazê-lo, ficando a sugestão para pesquisas futuras. 
Por fim, algumas recomendações gerais em termos de políticas públicas podem ser feitas, tomando como base Pessôa (2010). De forma resumida, o autor defende dois princípios básicos para o uso da melhor forma possível dos recursos provenientes da receita petrolífera: i) a renda petrolífera constitui uma riqueza e como tal deve ser tratada, ou seja, o poder público deve ter cautela ao decidir empregar a renda petrolífera em um programa específico; e, ii) embora haja na literatura fortes evidências de que rendas oriundas de recursos naturais não são eficientemente empregadas, o mesmo não se pode categoricamente afirmar para os municípios capixabas, conforme análise anterior, mas, de qualquer forma, há o entendimento de que a transparência constitui o instrumento mais poderoso para combater essas consequências indesejadas da abundância de recursos naturais. Por isso devem ser criados mecanismos e instituições que elevem o controle social sobre a renda petrolífera.

\section{Referências}

AGÊNCIA NACIONAL DO PETRÓLEO (ANP, 2011). Estatísticas de produção de petróleo e gás natural e de participações governamentais no Brasil e no Espírito Santo. Disponível em: <http://www.anp.gov.br>. Acesso em: 30 jun. 2011.

BARBOSA, D. H. Guia dos royalties do petróleo e do gás natural. Rio de Janeiro: Agência Nacional do Petróleo (ANP), 2001. 156 p. Disponível em: < http:/ / www.anp. gov.br>. Acesso em: 28 jun. 2011.

BREGMAN, D. Formação, distribuição e aplicação de royalties de recursos naturais: o caso do petróleo no Brasil. Dissertação (Mestrado em Economia) - Instituto de Economia, Universidade Federal do Rio de Janeiro, Rio de Janeiro, 2007.

CARNICELLI, L.; POSTALI, F. A. S. Royalties do petróleo e emprego público nos municípios brasileiros. In: ENCONTRO NACIONAL DE ECONOMIA (ANPEC), 40., 2012, Porto de Galinhas, PE. Anais... ANPEC, 2012a.

Rendas do petróleo e tributos locais: uma análise de propensity score. ENCONTRO NACIONAL DE ECONOMIA (ANPEC), 40., 2012, Porto de Galinhas, PE. Anais... ANPEC, 2012b.

CASELLI, F.; MICHAELS, G. Do oil windfalls improve living standards? Evidence from Brazil. NBER Working paper, 15550, 2009.

COSTA NOVA, L. Análise do impacto social de receitas provenientes de royalties do petróleo em municípios do estado da Bahia. Dissertação (Mestrado) - Universidade de Brasília, Brasília, 2005.

FEDERAÇÃODASINDÚSTRIASDO ESTADODORIO DE JANEIRO (Firjan). Índice Firjan de Desenvolvimento Municipal. Notas metodológicas, 2011. Disponível em: <http:/ / www.ifdm.firjan.org.br>. Acesso em: 28 out. 2011.

FREIRE, S.; MAGENTA, M. Bonança do petróleo não melhora cidades. Folha de São Paulo, São Paulo, p. A12, 31 out. 2011.

GRASSI, R. A.; CAÇADOR, S. B. Os impactos das participações governamentais nas finanças públicas e na economia do Espírito Santo. In: PIQUET, R.; SERRA, R. (Org.). Petróleo e região no Brasil: o desafio da abundância. 1. ed. Rio de Janeiro: Garamond, 2007.

HADDAD, E. A.; GIUBERTI, A. C. Economic impacts of pre-salt on a regional economy: the case of Espírito Santo, Brazil. In: EUROPEAN CONGRESS OF THE REGIONALSCIENCE ASSOCIATION INTERNATIONAL - Sustainable Regional Growth and Development in the Creative Knowledge Economy, 50., 19-23 ago. 2010, Jönköping, Sweden. Anais... , Jönköping, 2010.

INSTITUTO BRASILEIRO DE GEOGRAFIA E ESTATÍSTICA (IBGE). Estatísticas de PIB e população do Espírito Santo, 2011. Disponível em: <http:/ / www.ibge.gov.br>. Acesso em: 30 jun. 2011.

LEAL, J. A.; SERRA, R. V. Notas sobre os fundamentos econômicos da distribuição espacial dos royalties petrolíferos no Brasil. In: ENCONTRO NACIONAL DE ECONOMIA (ANPEC), 30., 2002, Nova Friburgo, RJ. Anais... Nova Friburgo, 2002.

MONTEIRO, J.; FERRAZ, C. Does Oil Make Leaders Unaccountable? Evidence from Brazil's off shore oil boom. PUC-Rio, 2010. (mimeo)

NAVARRO, C. A.S. Royalties do petróleo: estudo do caso de Campos dos Goytacazes. Dissertação (Mestrado em Economia Empresarial) - Universidade Cândido Mendes, Campos dos Goytacazes, 2003.

PESSÔA, S. A. O uso da renda petrolífera pelo Estado do Espírito Santo. In: VESCOVI, A. P. V. J.; BONELLI, R. (Org.). Espírito Santo: instituições, desenvolvimento e inclusão social. Vitória, ES: Instituto Jones dos Santos Neves, 2010, cap. 8, p. 269-292.

POSTALI, F. Renda mineral, divisão de riscos e benefícios governamentais na exploração de petróleo no Brasil. Rio de Janeiro: BNDES, 2002. 120 p.

Efeitos da distribuição de royalties do petróleo sobre o crescimento dos municípios no Brasil. In: ENCONTRO NACIONAL DE ECONOMIA (ANPEC), 35., 2007, Recife, PE. Anais... Recife, 2007.

POSTALI, F.; NISHIJIMA, M. Distribuição das rendas do petróleo e indicadores de desenvolvimento municipal no Brasil nos anos 2000. Estudos Econômicos, v. 41, n. 2, abr./jun. 2011.

QUEIROZ, C. R. A.; POSTALI, F. Rendas do petróleo e eficiência tributária dos municípios brasileiros. In: ENCONTRO NACIONAL DE ECONOMIA (ANPEC), 38., 2010, Salvador, BA. Anais... 2010, Salvador.

RIBEIRO, E.; TEIXEIRA, A.; GUTIERREZ, C. E. Impacto dos royalties do petróleo no PIB per capita dos municípios do Estado do Espírito Santo, Brasil. Revista Brasileira de Gestão de Negócios, v. 12, n. 34, jan./mar. 2010.

WOOLDRIDGE, J. M. Econometric analysis of cross section and panel data. Cambridge: MIT Press, 2002. 